\begin{tabular}{|c|c|c|}
\hline 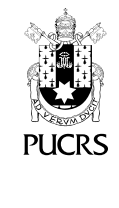 & $\begin{array}{l}\text { ESCOLA DE } \\
\text { HUMANIDADES }\end{array}$ & $\begin{array}{l}\text { Revista de Filosofia da PUCRS } \\
\text { Veritas, Porto Alegre, v. 66, n. 1, p. 1-6, jan.-dez. } 2021 \\
\text { e-ISSN: 1984-6746 | ISSN-L: 0042-3955 }\end{array}$ \\
\hline de) $h t p: / / d x$ & org/10.15448/1984-6746.2021.1.40210 & \\
\hline
\end{tabular}

SEÇÃO: TRADUÇÃO

\title{
Existe uma lógica jurídica? ${ }^{1}$
}

\author{
Is there a logic of law? \\ ¿Existe una lógica jurídica?
}

\section{Georges Kalinowski}

\section{Tomás Troster ${ }^{2}$}

orcid.org/0000-0002-2031-8919

ttroster@gmail.com

Recebido em: 24 fev. 2021.

Aprovado em: 18 ago. 2021.

Publicado em: 27 out. 2021.

\section{(c) (1)}

Artigo está licenciado sob forma de uma licença Creative Commons Atribuição 4.0 Internacional.
O número 4104 do Journal des Tribunaux (Bruxelas), de 22 de abril de 1956, publicou os Ensaios de lógica juridica ${ }^{3}$ de Marie-Thérèse Motte, do professor Paul Foriers e do professor René Dekkers, antecedidos por um preâmbulo de Robert Feys e seguidos pelas conclusões do professor Chaïm Perelman. ${ }^{4}$ Tais ensaios fazem parte das atividades do Centro Nacional de Pesquisas de Lógica" (CNRL) da Bélgica, "que há muitos anos colocou em seu programa - nas palavras de Robert Feys - o estudo dos complexos métodos utilizados de fato no raciocínio jurídico". Essas atividades do CNRL e os três ensaios publicados pelo Journal des Tribunaux nos levam a perguntar se existe uma lógica jurídica diferente da lógica pura e simples. ${ }^{6}$ E essa questão é apenas o fragmento de um problema mais importante, a saber, se existe apenas uma única lógica - ferramenta de toda atividade da razão, que encontra sua aplicação tanto na vida cotidiana como em qualquer ciência, seja na matemática, na física, na biologia, na história, na sociologia, na filosofia etc. - ou se existem várias lógicas - a lógica matemática, a lógica filosófica, a lógica

N. T.: O artigo original - "Y a-t-il une logique juridique?" - foi publicado em francês por Georges Kalinowski na revista Logique et analyse, v. 2, n. 5. p. 48-53, jan. 1959. Disponivel em: http://virthost.vub.ac.be/Lnaweb/ojs/index.php/LogiqueEtAnalyse/article/view/55/38. Acesso em: 8 ago. 2021. Agradeço imensamente à editora Peeters - detentora dos direitos de publicação do material original - pela permissão de uso concedida para fins da presente publicação. Este texto de Kalinowski - que surgiu como resposta a uma série de ensaios publicada em 1956 - deu origem a um intenso e profícuo debate. Ao contrário dos autores de tais ensaios - que defendiam a existência de diversas lógicas, entre elas uma lógica especial jurídica -, neste artigo, que tem como título a pergunta "Existe uma lógica jurídica?", Kalinowski responde negativamente à questão e argumenta a favor de uma única lógica pura e simples, da qual os raciocínios empregados na esfera do direito seriam meros tributários. Ironicamente, anos depois Kalinowski viria a escrever um livro intitulado Introdução à lógica juridica (1965), que recebeu o prefácio de ninguém menos que Chaïm Perelman, seu principal opositor no debate sobre a (in) existência de uma lógica especificamente jurídica.

Universidade Estadual do Norte do Paraná (UENP), Jacarezinho, PR, Brasil

$3 \quad$ N. T.: Os Essais de logique juridique aos quais Kalinowski se refere constituem um dossiê que preenche as catorze primeiras páginas ( $\mathrm{p}$. 261-274) do referido volume do Journal des Tribunaux de Bruxelas. Disponivel em: https://jt.larcier.be/archives/jt-1956-fr/jt_1956_4104. Acesso em: 8 ago. 2021. Como o próprio autor diz, trata-se de cinco trabalhos: o preâmbulo (ou "Avant-propos") de Richard Feys (que ocupa metade da página 261); e os textos (ou "communications") de Marie-Thérèse Motte (p. 261-266); Paul Foriers (p. 266-271); René Dekkers (p. 271-272); e Chaïm Perelman (p. 272-274). Esses textos ainda não estão disponíveis em português, mas pretendo traduzi-los e publicá-los futuramente - bem como os artigos que surgiram em resposta a este texto de Kalinowski. Nas notas da presente tradução, cito algumas passagens pontuais de tais textos para que o leitor consiga se situar no debate apresentado no artigo.

4 Embora alguns desses nomes apareçam de forma abreviada tanto na obra citada como no artigo de Kalinowski. optei por apresentá-los em sua forma completa, que é mais fácil de ser pesquisada. Na tradução, também descartei alguns pronomes de tratamento, principalmente em relação a Marie-Thérèse Motte, que é normalmente citada por Kalinowski como Melle (ou Mademoiselle, Senhorita).

5 N. T.: Kalinowski usa a expressão "Centre National Belge de Recherches de Logique" - abreviado "CNBRL" -, quando, na verdade, o termo "belga" (ou "belge") não faz parte nem do nome nem da sigla (CNRL).

$6 \quad$ N. T:: A expressão utilizada em francês é "logique tout court", que também poderia ser traduzida como "lógica simplesmente" ou "lógica sem mais". 
jurídica etc. Não tratarei esse problema aqui em sua totalidade. Nem mesmo procurarei dar diretamente uma resposta para a questão de saber se existe uma lógica especial juridica ou não. Apenas me limitarei a verificar se os artigos publicados na edição supracitada do Journal des Tribunaux fornecem realmente provas que dão sustentação para a tese de que existe uma lógica especial jurídica. E até para não entrar em tantos detalhes, irei me referir principalmente à comunicação de Marie-Thérèse Motte.

Nesse sentido, primeiro será preciso esclarecer o significado do termo "lógica", para, depois, explorar o conteúdo dos artigos em questão à luz de tal significado.

Neste artigo, entenderei por lógica ${ }^{8}$ pura e simples um conjunto de leis cientificas que estabelecem relações estáveis que - considerando certas circunstâncias - existem entre proposições dotadas de valor lógico, relações que são estabelecidas entre essas proposições tanto por seu valor lógico quanto por sua estrutura sintática. Chamarei de lógica teórica a lógica assim definida. O nome "lógica" pode ser atribuido por metonimia ao conjunto de regras de raciocínio garantidas pelas leis lógicas. A lógica assim entendida merece o nome de lógica normativa.

Algumas leis lógicas hoje são escritas com a ajuda de símbolos. Eis um exemplo muito simples de uma lei lógica: CПхfxfa. ${ }^{9}$ Para maior brevidade, nos referimos a ela pelo símbolo " $L 1$ " e a lemos assim: se para todo $x f x$, então $f a$. " $x$ " é uma variável nominal que permeia um conjunto de nomes; " $f x$ " simboliza toda função contendo a variável " $x$ "; " $a$ " é um nome concreto pertencente ao conjunto de nomes permeado pela variável " $x$ "; e "fa" é a proposição derivada da função " $f x$ " após a substituição da variável " $x$ " pelo nome " $a$ ", que é um dos valores da variável " $x$ ". A regra garantida por essa lei - regra que é uma das formas do dictum de omni $i^{10}$ e que designarei pelo símbolo "R1" - pode ser expressa da seguinte forma: aquele que aceitar a proposição "qualquer que seja o valor da variável ' $x$ ', é verdadeira a proposição resultante da função ' $f x$ ' pela substituição da variável ' $x$ ' por um de seus valores", também deve aceitar a proposição "fa". A relação estável estabelecida pela lei que funda esta regra existe desde que a seja um dos valores da variável " $x$ ". Tomemos mais um par de exemplos. Eis uma outra lei lógica, designada pelo símbolo " $L 2$ ": se todas as propriedades essenciais conhecidas de $A^{\prime}$ se assemelham às propriedades essenciais conhecidas de $A$, que aliás possui a propriedade $n$, $A^{\prime}$ provavelmente possui uma propriedade $n^{\prime}$ semelhante à propriedade $n$ de $A$. A relação estável estabelecida pela lei $L 2$ existe desde que as propriedades conhecidas de $A$ e $A^{\prime}$ sejam de fato essenciais. ${ }^{11} \mathrm{~A}$ regra de raciocinio garantida por esta lei - que chamarei de regra de indução por analogia e designarei pelo simbolo " $R 2$ " pode ser formulada da seguinte forma: aquele que aceitar a proposição "todas as propriedades essenciais conhecidas de $A$ ' se assemelham às propriedades essenciais conhecidas de $A$, que aliás possui a propriedade $n$ ", também deve aceitar a proposição " $A$ ' provavelmente possui uma propriedade $n$ ' semelhante à propriedade $n$ de $A$ ".

A noção de lei lógica aceita aqui é mais extensa do que a de lei lógica dedutiva: ela engloba não apenas leis absolutamente verdadeiras - que se verificam em todos os casos -, mas também leis prováveis - que não são verificadas em alguns casos. Entretanto, qualificarei como leis lógicas apenas aquelas que se verificam em mais de $50 \%$ dos casos. Pode-se ver bem que nossa noção de lógica, mais ampla do que aquela comumente utilizada, não se reduz apenas à lógica dos raciocínios dedutivos (lógica dedutiva), mas é aquela

\footnotetext{
N. T.: Via de regra, substituí o uso da primeira pessoa do plural pela primeira pessoa do singular, exceto nos casos em que o uso da primeira pessoa do plural também envolve a participação do leitor.

8 N. T.: Acrescentei alguns itálicos a termos ou expressões definidos ou contrastados pelo autor, a fim de ressaltá-los para o leitor

9 N. T.: Kalinowski faz uso da chamada notação polonesa. Como ele próprio descreve, a fórmula CПxfxfa - ou " $L 1$ " - deve ser lida como: "se para todo $x f x$, então $f a$ ". Na linguagem mais usual da lógica de predicado, a mesma fórmula pode ser escrita como: $\forall x F x \rightarrow F a$; ou então: $(x) F x \rightarrow F a$.

10 N. T.: Em latim, "aquilo que se afirma de todo". A expressão dictum de omni é normalmente utilizada para dizer que aquilo que se afirma de um conjunto ou classe de coisas também pode ser afirmado sobre todo e cada elemento de tal classe ou conjunto. No exemplo de Kalinowski, se $x$ é uma classe e possui um predicado qualquer e $a$ é um membro da classe $x$, então, $a$ possui esse predicado qualquer. ${ }_{11} \quad$ N. A.: Não discutirei aqui o que é uma propriedade essencial, como reconhecê-la e se isso é fácil ou não.
} 
de todos os raciocínios, quaisquer que sejam eles.

Uma vez que as leis lógicas estabelecem relações existentes entre proposições dotadas de valor lógico no que diz respeito aos elementos de ordem geral - tais como o valor lógico, a estrutura sintática, o pertencimento de um nome ao conjunto de valores de uma variável, o caráter essencial das propriedades atribuidas a um objeto etc. -, parece que as regras lógicas são igualmente gerais e, devido a essa generalidade, elas encontram sua aplicação em qualquer campo do conhecimento. Dito de outro modo, parece que existe uma única lógica com aplicações múltiplas. A mesma regra lógica, fundada sobre tal ou qual lei lógica, pode ser aplicada a um raciocínio não científico e a um raciocínio científico: matemático, físico, biológico, histórico, econômico, filosófico ou outro. Em outras palavras, não existem lógicas especiais: matemática, filosófica, juridica ou outra, mas sim aplicações de leis ou regras lógicas na matemática, na filosofia, na dogmática jurídica etc.

No entanto, algumas passagens dos textos publicados no Journal des Tribunaux parecem conter uma afirmação da existência de raciocinios jurídicos que são levados a cabo seguindo regras lógicas particulares, constituindo uma lógica normativa especial jurídica. ${ }^{12}$ Examinemos o conteúdo de tais textos para ver em que medida eles fornecem provas que de fato sustentem essa tese.

Marie-Thérèse Motte parece indicar ${ }^{13}$ dois raciocínios jurídicos específicos que saem dos limites da lógica pura e simples: o raciocinio extensivo (extensão) - pertencente ao grupo dos raciocinios metateóricos - e o raciocínio analógico (analogia). O raciocínio extensivo consiste na introdução de noções novas ou axiomas novos em um sistema dedutivo. ${ }^{14} \mathrm{O}$ raciocínio analógico, geralmente utilizado e conhecido, não é definido expressis verbis. ${ }^{15}$ Podemos defini-lo - para fixar as ideias - do seguinte modo: um raciocínio que segue a regra lógica $R 2$.

Primeiramente, uma retificação parece ser imprescindivel. A introdução de uma nova noção ou um novo axioma em um sistema dedutivo pode ser chamada de raciocínio? A extensão assim entendida e o raciocínio, qualquer que seja ele, são - tanto uma como o outro - ações, mas são duas ações tão diferentes que a extensão não pode ser chamada de raciocínio. O que é o raciocínio? É um processo mental de aceitação de uma proposição como verdadeira, que se deve ao reconhecimento anterior de uma outra proposição ou de outras proposições como verdadeiras, em certas circunstâncias que a tornam possivel ou mesmo necessária. O que é a extensão da qual fala Marie-Thérèse Motte? É um processo de introdução de uma nova noção ou de um novo axioma em um sistema dedutivo. ${ }^{16} \mathrm{~A}$ regra que indica a necessidade de fazer isso pode ser ela própria a conclusão de um raciocínio, mas, em si mesma, a ação de introduzir uma nova noção ou um novo axioma em um sistema dedutivo não é de modo algum um raciocínio!

Na realidade, então, não se trata de uma questão de raciocínio analógico e de raciocínio extensivo, mas sim de raciocínio analógico e - como veremos - de raciocínio segundo a regra lógica

12 N. A.: Ver o título Ensaios de lógica jurídica e o começo do preâmbulo de Robert Feys e também do texto de Marie-Thérèse Motte. IN. T.: As palavras iniciais do texto de Robert Feys ao qual Kalinowski se remete são: "Os raciocinios do direito têm sido frequentemente apresentados como simples aplicações das regras do silogismo ou da indução: uma concepção simplista, que corresponde apenas aos argumentos mais impessoais e às deduções mais elementares com base no texto legal". Já o texto de Marie-Thérèse Motte começa do seguinte modo: "Minha apresentação não se caracteriza como um estudo de doutrina: trata-se de um estudo de lógica do direito". Quer dizer, Kalinowski pretende destacar nesta passagem do texto que tanto o título da série - Ensaios de lógica jurídica - quanto os trechos iniciais dos dois primeiros artigos supõem a existência de uma lógica especial jurídica - ou lógica do direito - que não se limitaria à mera aplicação de regras lógicas gerais ao discurso jurídico - que é precisamente o que Kalinowski pretende refutar.]

${ }_{13}$ N. T.: Kalinowski usa a expressão "parece indicar" (em francês, "semble indiquer") porque, embora Motte não afirme explicitamente que os raciocinios em questão são exclusivos da argumentação jurídica, ela afirma que um "sistema jurídico", assim como um sistema dedutivo (mas não como um caso particular deste), pode ser o objeto de extensões - "através da introdução de noções novas e axiomas novos" - e de raciocínios por analogia.

14 N. T.: Em outras palavras, a extensão ou o raciocinio extensivo ao qual se refere Kalinowski é uma ampliação de um sistema dedutivo - que já dispõe de algumas proposições, princípios, postulados, definições e/ou axiomas - e que, por meio desse raciocínio extensivo, acrescenta um novo axioma e/ou uma nova noção (definição ou conceito), a partir dos quais poderá extrair conclusões ou fazer deduções, operando conjuntamente com os outros elementos que já faziam parte do mesmo sistema dedutivo.

15 N. T.: Em latim, "expressamente".

16 N. T.: Na seção III de seu texto, Marie-Thérèse Motte afirma categoricamente que a extensão no raciocínio juridico - exemplificada com a criação de um novo artigo no Código Civil belga para resolver uma imprecisão de um artigo anterior - seria incompativel com os moldes da lógica formal. Em suas palavras: "não é concebivel que, ao menos dentro de um mesmo sistema dedutivo rigoroso, sejam apresentados axiomas que depois precisem ser corrigidos" (1956, p. 268) 
dedutiva $R 1$, uma regra citada acima como o primeiro exemplo de regra lógica.

Tentemos ver em que medida esses dois raciocínios são raciocínios jurídicos, especiais, de modo que as regras lógicas segundo as quais eles são levados a cabo e as leis lógicas que garantem essas regras não fazem parte da lógica pura e simples, mas sim de uma lógica especial jurídica, anunciada pelo título geral dos textos publicados no Journal des Tribunaux. O que destaca Marie-Thérèse Motte em seu texto? Entre um raciocínio que segue a regra dictum de omni com a forma $R 1$ - citado como nosso primeiro exemplo de regra lógica (regra dedutiva) - e um outro que segue a regra lógica de indução por analogia $R 2$ - citado como nosso segundo exemplo de regra lógica -, Marie-Thérèse Motte opta pela aplicação da regra $R 1$ (dictum de omni). Uma vez que as normas do código civil belga que ordenam a instituição do usufruto e do quase usufruto $^{17}$ são universais, elas dizem respeito a todo usufruto ou quase usufruto, constituindo a extensão do conceito jurídico belga de usufruto ou quase usufruto. A noção geral de usufruto ou quase usufruto é um correspondente da variável $x$ em nossa lei lógica $L 1$ e em nossa regra lógica $R 1$. Se o caso em questão fosse um equivalente de a na mesma lei $L 1$ e na mesma regra $R 1$, seria sem dúvida necessário raciocinar de acordo com essa regra. Marie-Thérèse Motte pretende provar que o caso discutido sobre a aceitação do pagamento de um crédito por seu usufrutuário ${ }^{18}$ não vai além da essência do usufruto ou quase usufruto instituido tanto pela legislação belga quanto pela legislação francesa.

Entretanto, segundo o Tratado ${ }^{19}$ universalmente reputado do professor De Page, o caso em questão ultrapassa o conceito jurídico belga de usufruto ou quase usufruto e, consequentemente, não seria possivel raciocinar seguindo a regra $R 1$. Finalmente, as pessoas convocadas a interpretar a lei e aplicá-la ao caso em questão devem escolher um outro raciocínio, a saber, uma indução por analogia. De Page tenta provar que o caso discutido não pertence à extensão do conceito de usufruto ou quase usufruto e que, dadas as semelhanças - seja com o caso da tutela de um menor, seja com o de empresas comerciais, seja com o da expropriação conforme a lei francesa, seja, enfim, com alguns outros casos regulamentados pela legislação alemã, italiana e suiça - é necessário realizar um raciocínio por analogia.

Podemos optar por uma ou outra das presentes teses. Isso depende de nossa própria apreciação,

${ }_{17}$ N. T.: Em francês, "quasi-usufruit", que também poderia ser traduzido como "usufruto impróprio", a saber, o usufruto de bens consumiveis 18 N. T.: A questão discutida no texto de Marie-Thérèse Motte é apresentada pela autora da seguinte maneira: "Um crédito hipotecário pertence em usufruto a Silva e em nua propriedade a Souza. Pedro é o devedor da hipoteca.

"O crédito é a prazo e [...] Pedro vende o imóvel hipotecado a Paulo. Este pretende adquirir o imóvel quitado e livre de hipoteca. Para este fim, Pedro quer reembolsar o crédito exigivel. Ele propõe o reembolso ao usufrutuário. O nu-proprietário está no exterior e, devido a circunstâncias de guerra, não pode ser contatado.

"Pedro, como devedor hipotecário, sustenta que tem o direito de pagar o capital do crédito exigivel diretamente para o usufrutuário. Este último recusa, alegando que o consentimento do nu-proprietário é necessário. Pedro se apoia na tese jurídica de que o usufrutuário de um crédito tem o direito e até mesmo o dever de receber o capital devido. Que, consequentemente, ele, enquanto devedor, tem o direito de forçar o usufrutuário a receber o pagamento [...] e que, consequentemente, sendo liberatório o pagamento ao usufrutuário, ele tem o direito de obter o desembaraço da hipoteca.

"Estas são as circunstâncias do processo. Para reduzi-lo a um problema de lógica jurídica, eliminemos a questão da hipoteca. Na prática, ela deu origem ao litígio: a necessidade de obter o desembaraço para o devedor da hipoteca. Mas que o crédito seja ou não garantido por uma hipoteca (segurança real que segue o mesmo tipo do crédito principal) não muda nada, pelo menos do ponto de vista lógico, em relação à questão essencial - que recordamos:

"O usufrutuário de um crédito tem ou não o direito de receber o capital devido sem o consentimento do nu-proprietário?

"Nós colocamos a pergunta e raciocinamos de lege lata, do ponto de vista da lei existente" (1956, p. 261).

Segundo Motte, a resolução da questão inevitavelmente deve lidar com dois artigos do Código Civil belga, sendo o segundo uma espécie de raciocínio de extensão produzido pela insuficiência do primeiro. Ei-los:

Art. 578: "O usufruto é o direito de desfrutar, como se fosse o próprio proprietário, de coisas cujo proprietário é um outro, mas com a obrigação de preservar a sua substância".

Art. 587: "Se o usufruto envolve coisas que não podem ser usadas sem serem consumidas - como o dinheiro, grãos e bebidas -, o usufrutuário tem o direito de usá-las, mas na condição de devolvê-las na mesma quantidade, qualidade e valor no final do usufruto".

Na medida em que o usufrutuário do crédito no processo apresentado por Motte tinha como usufruto justamente os juros da divida mas não o capital principal -, se a divida fosse quitada, não haveria mais juros a receber por ela e, portanto, o usufruto de tal crédito (regido pelo artigo 578) passaria então a ser um quase usufruto (regido pelo artigo 587). Como Kalinowski mostra na sequência do texto - e a própria Motte considera em seu ensaio -, o conflito em questão poderia ser resolvido de duas maneiras distintas, a depender do raciocínio adotado - que, segundo Kalinowski, não seria exclusivo da argumentação juridica, mas também poderia ser verificado em outras diversas áreas do saber.

19 N. T.: Referência ao Traité élémentaire de droit civil belge [Tratado elementar de direito civil belga], de Henri De Page (1894-1969). 
por um lado, dos fatos e dos textos jurídicos e, por outro, de suas apreciações de uns e de outros, quer dizer, de nossa apreciação de seus argumentos positivos e negativos. Mas em toda essa discussão, não encontramos nada que testemunhe a existência de leis lógicas especiais jurídicas, regras lógicas especiais jurídicas ou uma lógica especial jurídica. Pelo contrário, podemos ver claramente - a introdução do texto de Marie-Thérèse Motte o diz quase expressis verbis - que os raciocinios entre os quais os debatedores hesitam são, na verdade, de aplicação universal e aparecem tanto na matemática, na filosofia ou na química, quanto na interpretação da lei positiva humana. É possivel introduzir uma nova noção ou um novo axioma em todo e qualquer sistema dedutivo - seja ele lógico, filosófico, matemático ou outro. Também é possivel raciocinar por analogia ${ }^{20}$ não apenas ao interpretar a lei positiva humana, mas também - como o demonstra o interessantíssimo Diálogo sobre a analogia, de Bruno de Solages - na matemática, na física, na química, na biologia, na história, na sociologia ou na filosofia.

Os raciocínios discutidos nos textos publicados no Journal des Tribunaux não têm, a meu ver, nada de especial do ponto de vista lógico.

E não existe nada de especial na aplicação feita pelo jurista das regras lógicas universais ao seu objeto próprio. O habitus ${ }^{21}$ jurídico - se é possivel usar esse termo - não é um habitus de alguns raciocínios não praticados fora do âmbito jurídico, mas, entre outros (para falar apenas daqueles mencionados pelos textos em questão), o habitus da constatação do pertencimento de uma coisa à extensão de um conceito jurídico (conceito pertencente à linguagem da lei positiva humana) ou - no caso de uma constatação contrária da inexistência em toda a lei positiva humana, escrita ou consuetudinária - de conceitos à extensão dos quais pertenceria a coisa em questão: o habitus da constatação de semelhanças essenciais com os designata ${ }^{22}$ de um outro nome de um conceito jurídico existente no vocabulário legal. O habitus jurídico proporciona várias outras constatações desse tipo para o jurista. Em geral, ele é um habitus de apreciação das normas jurídicas e dos fatos que estas são chamadas para gerir. É por isso que esse habitus implica, por um lado, um conhecimento suficientemente amplo e profundo da lei e, por outro, a prudência jurídica - uma das espécies da prudência em geral.

Existem, indubitavelmente, diversos saberes jurídicos: o saber do legislador que é chamado para instituir a lei; o saber de todos aqueles que devem aplicá-la aos casos concretos, primeiro do administrador público e do juiz, depois de todos aqueles que - como promotores, advogados, procuradores etc. - ajudam os primeiros e os segundos a fazê-lo. Há também o saber do jurista teórico que cria "a doutrina" - guia ou ajuda do jurista praticante. Cada um de tais saberes jurídicos requer seu próprio habitus intelectual. Mas nenhum habitus dentre esses é um habitus de raciocínios especificos que envolvem regras lógicas especificamente juridicas, leis lógicas especificamente jurídicas, em suma, uma lógica específica: a lógica jurídica. Existe, a meu ver, uma única lógica: a lógica pura e simples (quer a tomemos no sentido teórico ou normativo). Por outro lado, entre as várias aplicações das leis ou regras lógicas universais, existem aquelas que são feitas por juristas em um campo qualquer do saber jurídico. É muito interessante e extremamente útil analisar - nos diversos campos dos saberes jurídicos - as diferentes aplicações das leis e das regras lógicas universais. Também é curioso e enriquecedor examinar os habitus jurídicos aos quais essas aplicações se devem. Mas é vão procurar estudar uma lógica jurídica no sentido próprio da expressão, uma vez que ela não existe.

\footnotetext{
20 N. A.: O termo é usado aqui em seu sentido mais amplo, estendendo-se aos fatos, atos ou situações, assim como às coisas e às pessoas N. T.: Como destaca Erwin Panofsky, o conceito de habitus pode ser entendido como um "hábito mental" ou, mais precisamente, como "um principio que rege a ação" (Arquitetura gótica e escolástica, tradução Wolf Hörnke, São Paulo: Martins Fontes, 1991. p. 14). Ainda na mesma passagem, Panofsky ilustra o conceito: "tais hábitos mentais exercem sua ação em qualquer cultura: qualquer moderno livro de história está impregnado da ideia de evolução (ideia essa que devia ser objeto de um questionamento muito mais profundo do que o que tem havido até aqui [...]); todos nós também operamos despreocupadamente com conceitos como insuficiência vitamínica, alergia, fixação materna ou complexo de inferioridade, sem um conhecimento exato de bioquímica ou psicanálise" (grifos meus).

22 N. T.: Em latim, designata são os objetos aos quais um termo se refere (ou seja, que são designados por ele).
} 


\section{Agradecimentos}

Para a presente tradução, agradeço às preciosas elucidações e correções feitas por meus estimadissimos amigos Roger Xavier, Elise Boorée, Luccas Gissoni e Pedro Falcão - além das excelentes sugestões feitas pelos pareceristas.

\section{Tomás Troster}

Doutor em Filosofia pela Universidade de São Paulo (USP), em São Paulo, SP, Brasil; e bacharel e licenciado em Filosofia pela Pontificia Universidade Católica de São Paulo (PUC-SP), em São Paulo, SP, Brasil; professor do Colegiado de Filosofia da Universidade Estadual do Norte do Paraná (UENP), em Jacarezinho, PR, Brasil; e professor colaborador do Centro de Estudos do Direito Econômico e Social (CEDES), em São Paulo, SP, Brasil.

\section{Endereço para correspondência}

Tomás Troster

Universidade Estadual do Norte do Paraná

Campus de Jacarezinho

Centro de Ciências Humanas e da Educação - CCHE

Centro de Letras, Comunicação e Artes - CLCA

Rua Padre Melo, 1.200,

Jardim Marimar, 86400-000

Jacarezinho, PR, Brasil

Os textos deste artigo foram revisados pela Poá Comunicação e submetidos para validação do autor antes da publicação. 